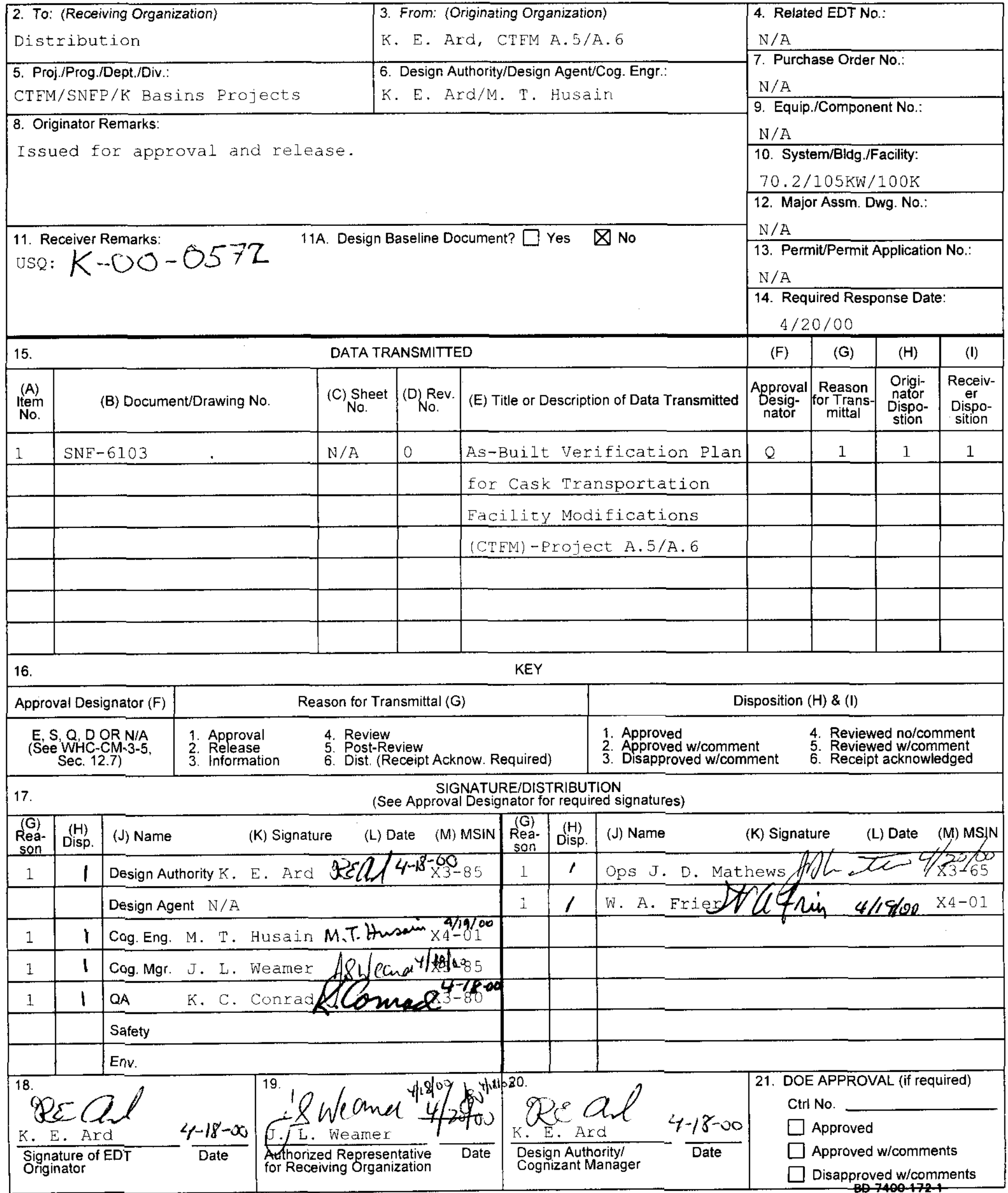


SNF-6103

Revision 0

\section{As-Built Verification Plan for Cask Transportation Facility Modifications (CTFM) - Project A.5/A.6}

Prepared for the U.S. Department of Energy

Assistant Secretary for Environmental Management

Project Hanford Management Contractor for the

U.S. Department of Energy under Contract DE-AC06-96RL13200

\section{Fluor Hanford}

P.O. Box 1000

Richland, Washington 
SNF-6103

Revision 0

EDT 629209

\section{As-Built Verification Plan for Cask Transportation Facility Modifications (CTFM) - Project A.5/A.6}

K. I. Lane

Fluor Hanford

Date Published

April 2000

Prepared for the U.S. Department of Energy

Assistant Secretary for Environmental Management

Project Hanford Management Contractor for the

U.S. Department of Energy under Contract DE-AC06-96RL13200

\section{Fluor Hanford}

P.O. Box 1000

Richland, Washington

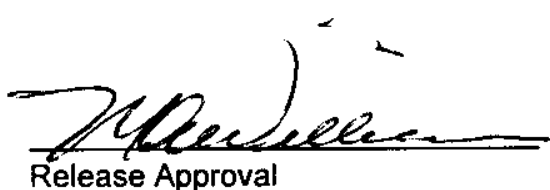

Release Approval
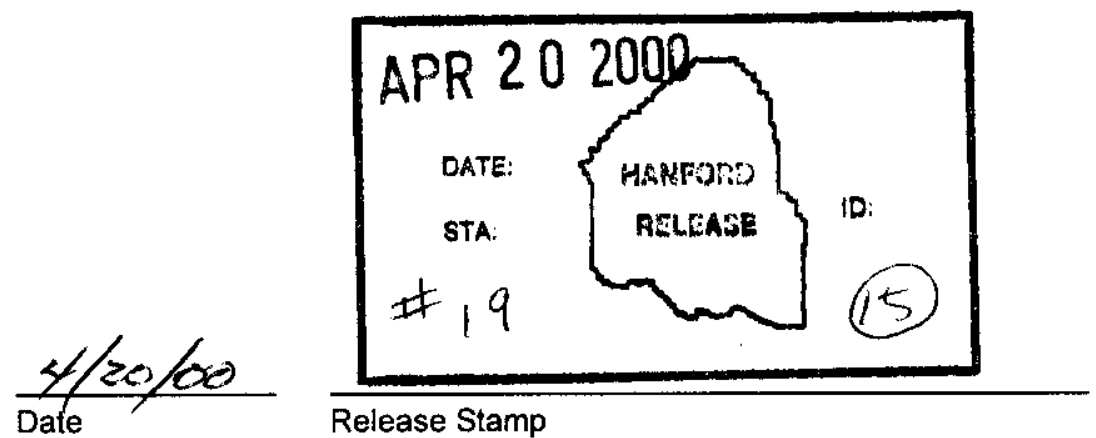
TRADEMARK DISCLAIMER

Reference herein to any specific commercial product, process, or service by trade name, trademark, manufacturer, or otherwise, does not necessarily constitute or imply its endorsement, recommendation, or favoring by the United States Government or any agency thereof or its contractors or subcontractors.

This report has been reproduced from the best available copy. Available in paper copy and microfiche.

Available electronically at http://www.doe.gov/bridge. Available for a processing fee to the U.S. Department of Energy and its contractors, in paper, from:

U.S. Department of Energy

Office of Scientific and Technical Information

P.O. Box 62

Oak Ridge, TN 37831-0062

Phone: 865-576-8401

Fax: 865-576-5728

Email: reports@adonis.Osti.gov(423)576-8401

Available for sail to the public, in paper, from:

U.S. Department of Commerce

National Technical Information Service

5285 Port Royal Road

Springfield, VA 22161

Phone: $800-553-6847$

Fax: 703-605-6900

Email: orders@ntis.fedworld.gov

Online ordering:

http://www.ntis.gov/ordering.htm

Printed in the United States of America

Total Pages: $\times 34(J K B+120100)$ 


\section{FOREWORD}

This As-built Verification Plan (AVP) establishes a uniform and systematic process to ensure essential technical information shown on engineering drawings accurately depicts the physical configuration of the project work installed in $105 \mathrm{~K}$ West (KW) Basin and that essential components are accurately indexed in the KW component index data base. This document defines and implements processes to be performed for selected drawings and indexed components for structures, systems, and components, (SSCs), required to support the successful completion of project turnover. The information obtained from the field verification process reflects the actual physical configuration and identifies any discrepancies discovered between the field condition and approved drawings and components in the component index. 


\section{TABLE OF CONTENTS}

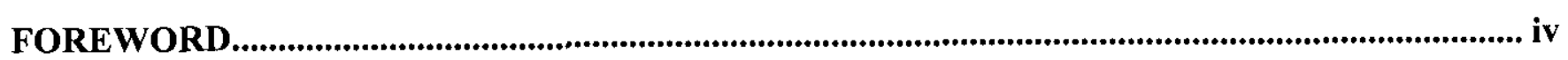

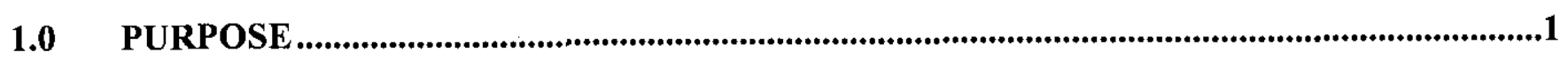

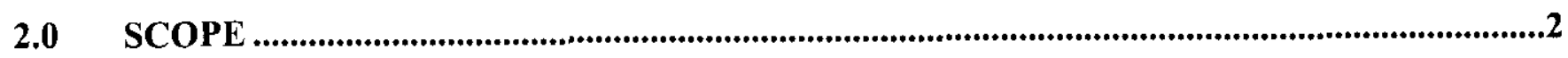

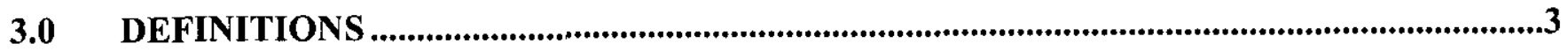

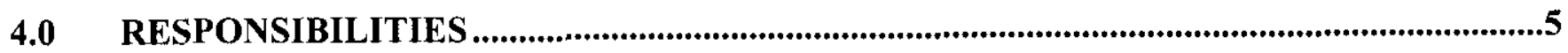

4.1 FLOUR HANFORD COMPANY .........................................................................................5

4.1.1 Project Manager..............................................................................................................5

4.1.2 Project Design Authority (DA) …….................................................................5

4.1.3 Project Lead Engineer (PLE) ....................................................................................5

4.1.4 Quality Assurance........................................................................................................6

4.1.5 Facility Engineering Manager .............................................................................6

4.1.6 Project Engineering Manager...............................................................................6

4.1.7 Facility Cognizant Engineer (CE)/Design Authority (FDA)...............................6

4.1.8 Walkdown Team Leader ............................................................................................6

4.1.9 Walkdown Team Members...........................................................................................7

5.0 FIELD VERIFICATION PROCESS .....................................................................................8

5.1 FIELD VERIFICATION METHODS .........................................................................................8

5.2 PRE-WALKDOWN ACTIVITIES ....................................................................................8

5.3 VERIFICATION PACKAGES ......................................................................................................8

5.3.1 Project Drawing Verification Packages .........................................................................8

5.4 VERIFICATION WALKDOWNS.............................................................................................9

5.4.1 Visually Tracing the System .................................................................................9

5.4.2 Discrepancies ...............................................................................................................9

5.4.3 Documenting Discrepancies .......................................................................................9

5.4.4 Justifying the Documented Difference ..................................................................10

5.5 REVIEWING THE MARK-UP DRAWING .............................................................................10

5.5.1 Checking the Drawing .................................................................................................11

5.6 DRAWING REVISION/RELEASE ..............................................................................11

5.6.1 ECN Incorporation Prior to AVP Activities ..........................................................11 
5.6.2 Direct Revision ECN

5.7 Closing Out the Verification Package

5.7.1 Assembling the Package Document............................................................11

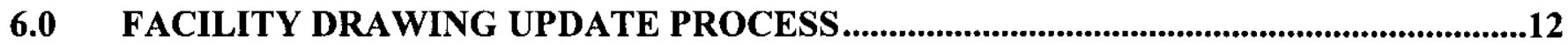

6.1 PROCESS FOR UPDATE AFFECTED FACILITY DRAWING .................................................12

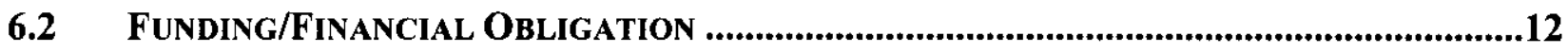

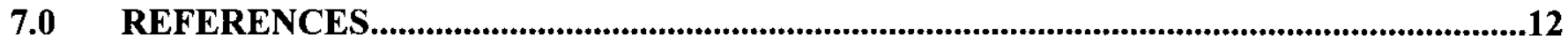

\section{LIST OF APPENDICES}

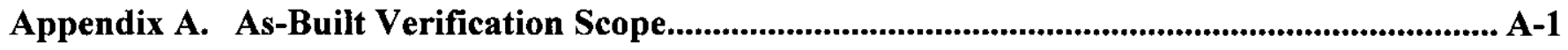

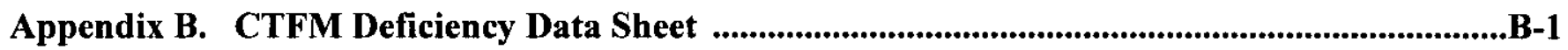

Charge Code: $105463 / \mathrm{B} 000$

B\&R Code: $\quad$ EW04J1110

Key Words: Cask Loadout System (CLS), Cask Transportation Facility Modifications (CTFM), As-Built, Multiple Canister Overpack (MCO) Loading System (MLS).

Abstract: This document establishes an As-built Verification Plan (AVP) for implementing requirements in PHMC Engineering Requirements HNF-PRO-1819, Rev. 4, Sections 2.8.3.d and 2.10.8 and Spent Nuclear Fuels (SNF) Project Administrative Procedure EN-6-012-01. This AVP defines and implements approved processes to document the physical configuration of the project scope installed within the facility and identify discrepancies between the associated project engineering drawings and the field configuration, and the component index (CI) database as defined in AP EN 6-005-02. This AVP defines requirements for project activities verifying conformance of structures, systems, and components (SSCs) to project specified requirements. 


\subsection{PURPOSE}

This document establishes an As-built Verification Plan (AVP) for implementing requirements in PHMC Engineering Requirements HNF-PRO-1819, Rev. 4, Sections 2.8.3.d and 2.10.8 and Spent Nuclear Fuels (SNF) Project Administrative Procedure EN-6-012-01. This AVP defines and implements approved processes to document the physical configuration of the project scope installed within the facility and identify discrepancies between the associated project engineering drawings and the field configuration, and the component index $(\mathrm{CI})$ database as defined in AP EN 6-005-02. This AVP defines requirements for project activities verifying conformance of structures, systems, and components (SSCs) to project specified requirements. 


\section{SNF-6103, Rev. 0 \\ Project A.5/A.6}

\subsection{SCOPE}

The scope of this AVP is limited to SNF Project Subproject Cask Transportation Facility Modification (CTFM) A.5/A.6. The scope of project work to be as-built verified by the processes identified in this AVP is defined by the Cask Loadout System (CLS), Design Authority (DA) with concurrence from facility and other subproject DA's responsible for SSCs that interface with CLS SSCs. The SSCs, engineering drawings, and boundary descriptions to be as-built are identified in Appendix A. Only one as-built verification effort is required for the scope identified within this document. Verification shall be made after completion of construction; thus no mandatory hold points are required.

Engineering drawings designated as essential drawings by the CLS DA shall be completely field verified. Engineering drawings designated as support drawings by the CLS DA shall be partially or completely field verified as identified in Appendix A. Engineering drawings designated as general drawings may be partially or completely field verified as identified in Appendix A. All as-built stamped engineering drawings provided by vendors shall have all work completed Engineering Change Notices (ECNs) incorporated and be field verified per HNF-PRO $1819 \mathrm{Rev} 4$, Section 2.8.3.d.

This AVP requires that ECNs designated as modification work are signed off as work complete and a copy of the signed sheet of that ECN has been delivered to a Hanford Site Document Control (HSDC) release station. ECNs generated against existing facility drawings and designated as modification work shall be as-built verified by administrative procedures identified in the engineering change control process, work control process and the configuration management plan and are not included in the scope of this AVP.

Verification of vendor supplied drawings marked as "as-built" drawings and approved by the project DA do not require further as-built field verification and therefore are not included in the scope of this plan.

This AVP enumerates the following:

- The scope of the project that requires As-Built Verification.

- Approved methods for verifying as-built condition of required project scope.

- Participant positions and their respective task responsibilities.

- Approved processes to identify, resolve and document discrepancies between as-built configuration and project design drawings and between the $\mathrm{K}$ West $(\mathrm{KW})$ component index and project design drawings. 


\subsection{DEFINITIONS}

As-built drawing - an engineering drawing depicting the actual physical configuration as confirmed by field walkdown.

As-built field verification - approved processes entailing field inspections that ensures the documentation of the physical installation of SSCs is accurately indicated on engineering drawings.

As-built verification - approved processes ensuring engineering drawings of SSCs accurately indicate the physical configuration of the facility.

Check print - a copy of a drawing used for comparison or verification.

Cognizant engineer - the person appointed by the SNF Project chief engineer to maintain cognizance of installed facility and process systems. Cognizant engineers provide technical guidance to the maintenance and operations organizations for operating facility processes, procedures, and activities.

Component index (CI) - an index of all components vital to the operation and maintenance of the $\mathrm{K}$ Basins facility. It lists the components by tag number, type of component, manufacture, physical location, and rating, etc.

Component test procedure (CTP) - a procedure used by the Startup Engineering to qualify the installation. A procedure used by Startup Engineering to ensure acceptability of completed construction scope prior to turnover to Operations.

Covered item - part of SSCs that will be hidden from view or inaccessible for visual inspection due to subsequent work.

Design authority - the person appointed by the SNF Project chief engineer to be uniquely responsible and accountable for final acceptability of a SSC and its design baseline.

Discrepancy - a difference between the physical configuration observed in the field and what is shown on the drawing.

Discrepancy data sheet (DDS) - data sheet used to document discrepancies between the project drawing or CI items and SSCs in the field. A copy of this DDS is included in this FVP as Appendix B.

Drawing category - the three drawing categories assigned to project drawings are essential (E), support (S), and general (G). Priority in field verification is given first to (E) followed by (S) drawings.

Field drawings - a set of the drawings marked up to reflect as-constructed condition and used by the field walkdown verifier during the walkdown phase of the data collection process. 
Field verification - the process of identifying the updated engineering drawings and all associated changes, performing a field walkdown, documenting the as-found condition, and reconciling any differences. This process may also include the testing of systems and components to ensure compliance with functional requirements.

Field verification package index - data sheet listing documents used to field verify a project drawing or component with actual field configuration.

Independent checking - a review of the field verified drawings conducted by individuals who have not participated in the walkdown of the SSC.

Non-compliance report (NCR) - a report that may be used during Quality Assurance/Quality Control (QA/QC) audits of field verified drawings, to document a discrepancy with the verified drawing.

Surveillance report - a report that may be used during QA/QC audits of field verified drawings, to document a discrepancy with the verified drawing.

Verification package - a project record that documents the elements of the walkdown/field verification process.

Walkdown (field verification walkdown) - a visual inspection of SSCs to identify the as-found physical configuration and any discrepancies with currently approved facility documentation. The field walkdown may include verification "ringing-out" of electrical circuits (P\&IDs, electrical one lines) as specified by the project cognizant engineer and facility cognizant engineer.

Walkdown team lead - the person designated by the design authority or cognizant engineer to witness and document the execution of a field verification plan. For this plan the walkdown team lead shall be the PLE unless otherwise designated by the DA. 


\subsection{RESPONSIBILITIES}

\subsection{FLOUR HANFORD, INC.}

\subsubsection{Project Manager}

- Approve and implement this as-built field verification plan.

- Provide Preventative Maintenance (PM) support for the as-built verification process, including approving the schedule, staffing, and funding for the as-built verification process.

- Verify DDSs are controlled.

- Ensure the verification packages are transmitted to Technical Document Control and LMSI maintained Project Files.

\subsubsection{Project Design Authority (DA)}

- Approve this Field Verification Plan.

- Approve the dispositions to discrepancies generated by the as-built verification processes, including those identified by QA random checks.

- Verify relevant ECNs have been incorporated into the appropriate verification package prior to asbuilt field verification walkdowns.

- Approve resolution of discrepancies, and obtain appropriate concurrence as necessary from the $\mathrm{K}$ Basin facility and systems DAs or cognizant engineers.

- Approve the completed as-built field verified print.

- Approve for release the as-built project drawings.

- Identify for field verification, the critical characteristics and requirements for indexed components.

- Identify and approve the method(s) by which identified SSCs are field verified.

\subsubsection{Project Lead Engineer (PLE)}

- Maintain a discrepancy logbook

- Maintain the completed DDSs.

- Verify the field verified drawings and the disposition of discrepancies.

- Prepare the as-built field verification packages. 
- Resolve discrepancies identified by the as-built field verification process.

\subsubsection{Quality Assurance}

- Approve this plan (ensure this AVP is adequately comprehensive and procedurally compliant).

- Provide oversight surveillance of the AVP process.

- Report unsatisfactory findings in writing to the DA. This may be done using a NCR or surveillance report.

\subsubsection{Facility Engineering Manager}

Approve this AVP, including concurrence with the identified scope and respective method for as-built field verification.

\subsubsection{Project Engineering Manager}

- Ensure that all walkdown team members are qualified and trained to perform walkdown functions and, if necessary, impose additional training and/or requiring proficiency demonstration prior to allowing individuals to perform as-built field verification walkdowns.

\subsubsection{Facility Cognizant Engineer (CE)/Design Authority (FDA)}

- Approve this AVP.

- Obtain the concurrence of the K Basin system cognizant engineers in identifying the systems to be verified and the methods employed for each system verification.

\subsubsection{Walkdown Team Leader}

- Prepare field verification packages for each drawing and select CI requiring as-built field verification.

- Verify with Hanford Site Document Control that all existing ECNs are incorporated for each verification package prior to field verification activities. This action also includes incorporation of all drawing markups.

- Disposition discrepancies found by the walkdown team per DA direction.

- Provide information to the DA/PE for ECNs of the field verification changes.

- Schedule and coordinate personnel required to open specific panels, cabinets, motor control centers, etc., to support visual observation for as-built field verification activities. 
- Ensure completed verification packages are assembled and submitted to the DA for approval.

\subsubsection{Walkdown Team Members}

- Perform field verification according to AVPs provided by the PLE.

- Provide input to the walkdown team leader for discrepancies encountered between the field and the design drawings/CI.

- Inform the PLE when he/she feels that they do not have the qualifications/knowledge necessary to perform the field verification activities they have been assigned.

- Verify that for all accessible SSCs specified on the drawing match the field configuration. 


\subsection{FIELD VERIFICATION PROCESS}

The project DA, with concurrence from facility DA(s) as appropriate, shall determine which technical information requires as-built field verification based on operational requirements to meet the facility mission. The DA indicates as-built field verification boundaries for SSCs on all drawings requiring asbuilt field verification. This may encompass the entire drawing or any portion thereof. The DA also indicates the type of information and which of the $\mathrm{CI}$ items require labeling verification.

\subsection{FIELD VERIFICATION METHODS}

Acceptable methods of as-built verification to document the configuration of critical technical information on SSCs have been defined and are listed below. At the discretion of the project DA, noncritical information shall not require as-built verification. For critical information, previous activities and their documentation verifying as-built configuration, (FATs, CATs, PATs, CTPs, construction work packages, and vendor as-built drawings), may be acceptable and shall be used whenever possible. When the DA rules that previous efforts are not acceptable, as-built field verification shall be by Method 2 described below.

- Method 1 - This includes: 1) Project scope that the DA identifies as not requiring as-built field verification, 2) Facility modifications where confirmation of ECN work completion is documented by the ECN process for scope identified as modification work, 3) For vendor supplied drawings where previous vendor as-built efforts are acceptable to the DA.

- Method 2 - Perform as-built verification walkdown of identified structures, systems, and components to verify critical characteristics. For scope verified by method 2, the DA shall identify critical characteristics on drawings and boundaries for as-built field verification scope as indicated in Appendix A.

\subsection{PRE-WALKDOWN ACTIVITIES}

Prior to as-built verification, facility drawings used by the project and all project drawings shall be assigned an essential (E), support (S), or general $(G)$ category. The method of as-built verification for a particular scope shall be identified prior to walkdown. ECNs generated against LMSI controlled project drawings listed in Appendix 1 shall be verified as complete prior to initiating the field verification walkdown

\subsection{VERIFICATION PACKAGES}

\subsubsection{Project Drawing Verification Packages}

The PLE will ensure the as-built field verification packages are ready for field verification. Unless otherwise specified by the DA, the package shall include a field verification package index, drawings and a copy of outstanding ECNs. Any reference drawings used to aid this process shall be examined for outstanding ECNs. 


\subsection{VERIFICATION WALKDOWNS}

Only individuals qualified and trained to the requirements of AP EN 6-012 shall participate in the walkdowns. A comparison will be made between the physical configuration and the drawing configuration.

\subsubsection{Visually Tracing the System}

Within the scope designated by the DA and delineated in Appendix A, applying ALARA principles, each system component shall be visually verified to the fullest extent practicable. The verification team will perform a systematic walkdown of the system. Within the scope of the verification package, the walkdown team will clearly indicate on the drawing: 1) areas that are not able to be verified due to restricted access or other reasons, 2) discrepancies between the drawings and the facility configuration, including equipment that has been abandoned or is not in service.

\subsubsection{Discrepancies}

If discrepancies between the drawings and the facility are identified, the walkdown team lead shall show the actual configuration on drawings in the as-built field verification package, ensure that all members of the verification walkdown team concur, then indicate so by signing and dating the correction. The signatures attest to the fact that the individual(s) visually observed and indicated concurrence that the marked-up drawing accurately depicts the existing plant configuration for the parts of the drawing, not noted as inaccessible, contained within the boundaries being verified.

Reference drawings may be used to assist walkdown personnel in the location of components within the boundaries of the walkdown. These reference drawings may provide information that shows layout, elevation, or alternate system perspectives. The information on the marked-up field copy of the drawing may be transcribed onto a consolidated drawing for improved clarification.

\subsubsection{Documenting Discrepancies}

- Noted discrepancies are reported on the project DDS. The DDS shall be maintained by the PLE. The drawing number and zone location are included in the DDS entry to identify the location of each discrepancy on the marked-up drawing. The marked up drawing shall reference the discrepancy logbook entry number. The DDS shall also report discrepancies with the CI database. Each discrepancy shall be dispositioned by the PLE and approved by the DA.

- For components that are not labeled in the field, the walkdown member notes the condition on the DDS entry. No attempt will be made to inspect internal sub-components except as requested by the DA or the facility CE. During the walkdowns, general condition of facility SSCs and housekeeping should also be observed and any damaged components or irregularities should be reported in the variance logbook. 


\subsubsection{Justifying the Documented Difference}

The PLE shall assist the DA in justifying the difference(s) between the drawing and the field configuration (e.g., ECNs). If the documents cannot be found justifying the difference(s), the DA shall determine the following:

Is the configuration required for safe operation of the system?

If $\mathrm{NO}$, proceed to dispositioning the discrepancies per DA direction.

If YES, the DA will determine if the configuration is safe to operate. If determined not safe to operate, then take immediate remedial action. If the configuration is safe to operate, then disposition the discrepancy by completing the DDS.

Is the discrepancy disposition accept-as-is?

If YES, the PLE shall assist the DA to prepare an ECN to reconcile the discrepancy between the physical configuration and the drawing. The DA/PLE will process the ECN per existing SNF procedures and practices. The DA/PLE will obtain approval for the ECN as work-complete and incorporate the ECN on the field verified drawing for drawings in the LMSI system.

Upon completion, this work shall be documented on the DDS.

If NO (i.e., the disposition is other than accept-as-is), determine the following:

Should the hardware (physical configuration) be restored to the drawing requirements?

If $\mathrm{YES}$, the DA/PE shall ensure the configuration is altered to match the drawing, and will document this on the DDS. An ECN is not required since the drawing is the governing document.

If $\mathrm{NO}$, the DA/PLE shall prepare an $\mathrm{ECN}$ to describe the required changes. Upon completion, this work shall be documented on the DDS.

\subsection{REVIEWING THE MARK-UP DRAWING}

The walkdown team leader reviews the discrepancies listed in the DDS and on the marked-up drawing, and obtains disposition for discrepancies from the DA/PE. For those discrepancies involving areas that are inaccessible, determine if further verification is required:

If YES, Design Services documents the disposition.

If NO, the DA and the project engineers may provide as-built verification through alternate means (e.g., by surveillance, loop calibration, functional test, etc.). 


\title{
5.5.1 Checking the Drawing
}

A check print will be developed after all walkdown information is incorporated on the drawing. This check print is used by an independent checker to ensure that the original walkdown and drawing incorporation are correct. This approved check print will be added to the verification package.

\subsection{DRAWING REVISION/RELEASE}

\subsubsection{ECN Incorporation Prior to AVP Activities}

This activity applies only to LMSI controlled drawings generated by the CTFM Project as directed by the DA. ECNs will be prepared as outlined in SNF AP EN-6-039.

Each drawing will specify the following in the drawing revision block:

"UPDATED PER FIELD VERIFICATION ECN XXXXXX

AS-BUILT FOR PROJECT K WEST CTFM

INCORPORATED ECNs, XXXXXX, XXXXXX"

or

\author{
"UPDATED PER PARTIAL FIELD VERIFICATION ECN XXXXXX \\ FOR PROJECT K WEST CTFM \\ INCORPORATED ECNs, XXXXXX, XXXXXX"
}

or

"K WEST CTFM PROJECT TURNOVER PER ECN XXXXXX"

or

\author{
"K WEST CTFM PROJECT TURNOVER AS-BUILT BY VENDOR \\ SEE VENDOR INFORMATION FILES XXXXX, \\ INCORPORATED ECNs XXXXXX, XXXXXX"
}

The following block will be added outside the border in the upper right hand corner:

"FOR FIELD VERIFICATION STATUS SEE REV. X" 


\subsubsection{Direct Revision ECN}

This activity applies only to LMSI controlled drawings generated by the CTFM Project. A direct revision ECN may be written to document the completion of As-Builting and Field Verification, if required by the DA. The ECN will include the following:

- This direct revision updates drawing H-1-XXXXX Sheet X Revision X per (this document \#), Revision X, Field Verification Plan for K WEST CTFM Project

\subsection{CLOSING OUT THE VERIFICATION PACKAGE}

\subsubsection{Assembling the Package Document}

The verification package shall be retained by the SNF Project Files as a quality record and upon completion of this program shall be transmitted by the SNF Project Files to the Records Holding Area as a lifetime quality record in accordance with RIDS. The verification package may include:

- Copy of the DDS entry

- Original check print(s) (signed)

- Annotated draft CAD drawing(s) (signed) if drawing chosen for random check

- Marked-up drawing(s)

- AS-FOUND drawing

- Correspondence associated with drawing verification

- Revised/issued drawing 


\subsection{FACILITY DRAWING UPDATE PROCESS}

\subsection{PROCESS FOR UPDATE AFFECTED FACILITY DRAWING}

To assure configuration control, the project drawing needs to be integrated into the existing facility drawing. The facility $\mathrm{CE}$ for each affected system will specify which drawings are impacted by the project and identify how to accomplish this task.

\subsection{FUNDING/FINANCIAL OBLIGATION}

The funding for project as-built/field verification drawings will be provided by the SNF Project, CTFM Subproject. The Project will have the financial responsibility for the as-built/field verification of all project drawings through turnover. After turnover, K Basin Operations will have the responsibility of keeping drawings current.

\subsection{REFERENCES}

HNF-PRO-1819, "PHMC Engineering Requirement"

SNF AP EN-6-012-01 "As-Built Verification Process"

SNF AP EN-6-039-00 "Engineering Document Change Control Requirements" 
SNF-6103, Rev. 0

Project A.5/A.6

APPENDIX A

AS-BUILT VERIFICATION SCOPE

CONSISTING OF 13 PAGES

INCLUDING COVERSHEET

Page A-1 
SNF-6103, Rev. 0

Project A.5/A.6

APPENDIX A

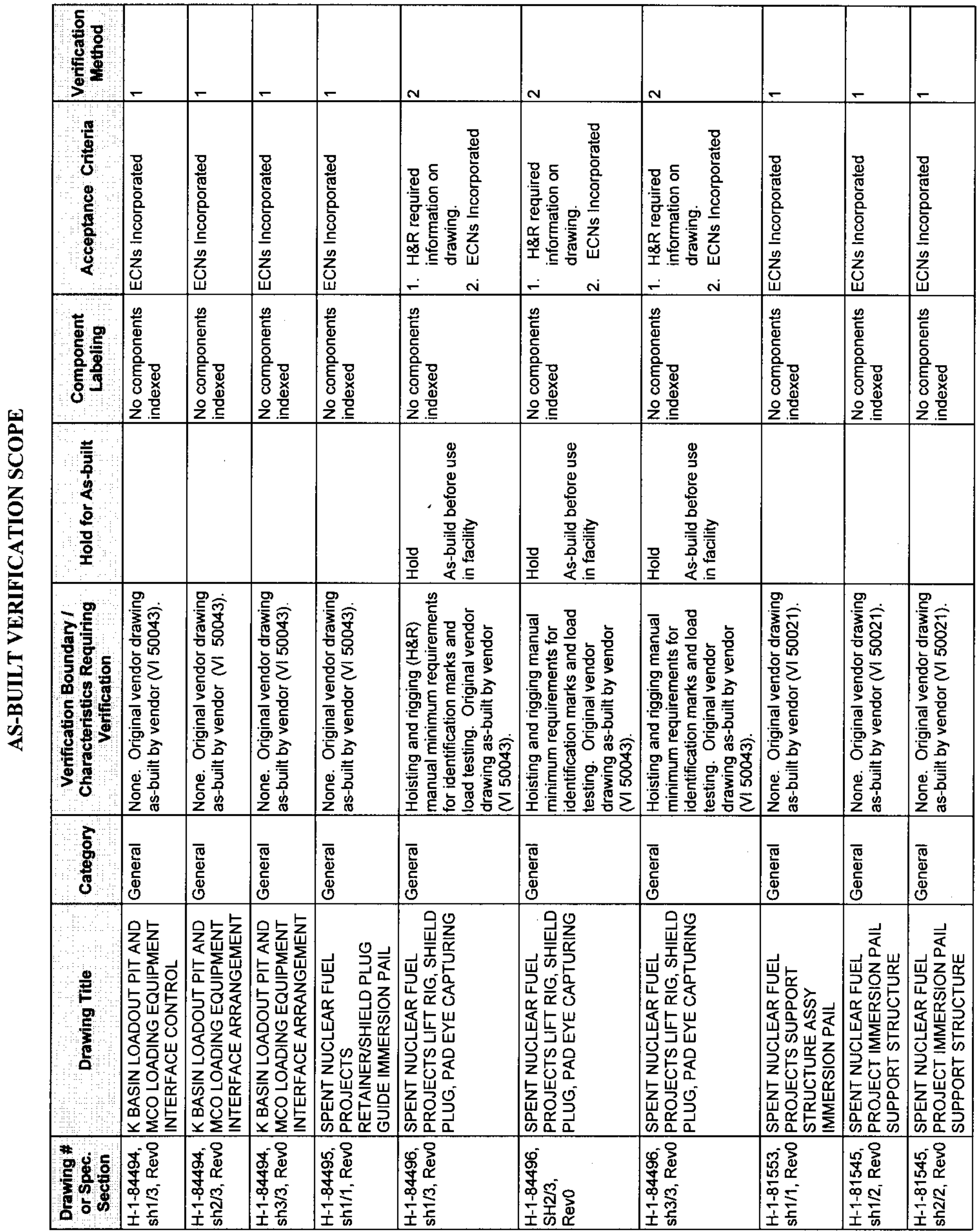

Page A-2 
SNF-6103, Rev. 0

Project A.5/A.6

APPENDIX A

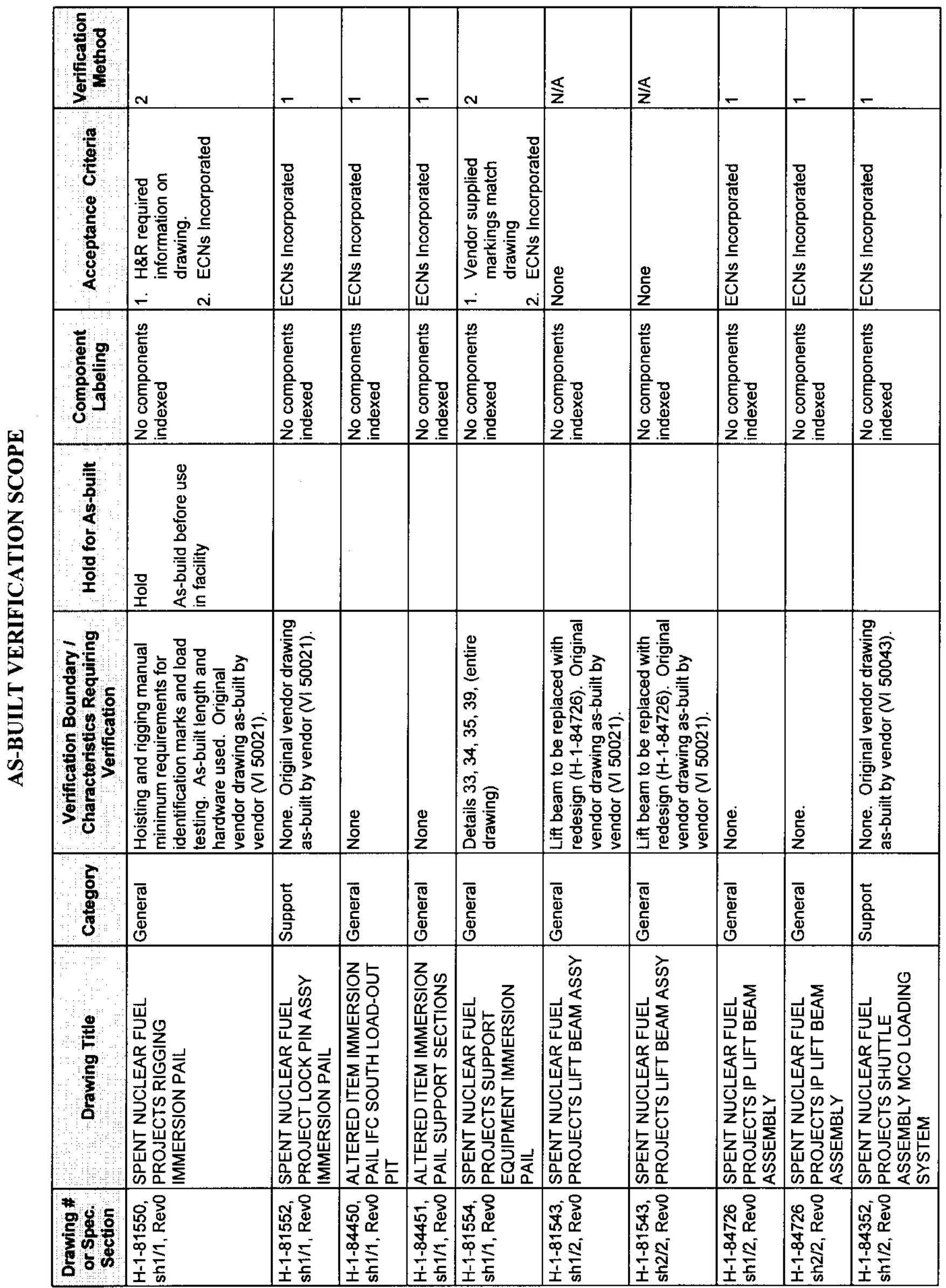

Page A-3 
SNF-6103, Rev. 0

Project A.5/A.6

APPENDIX A

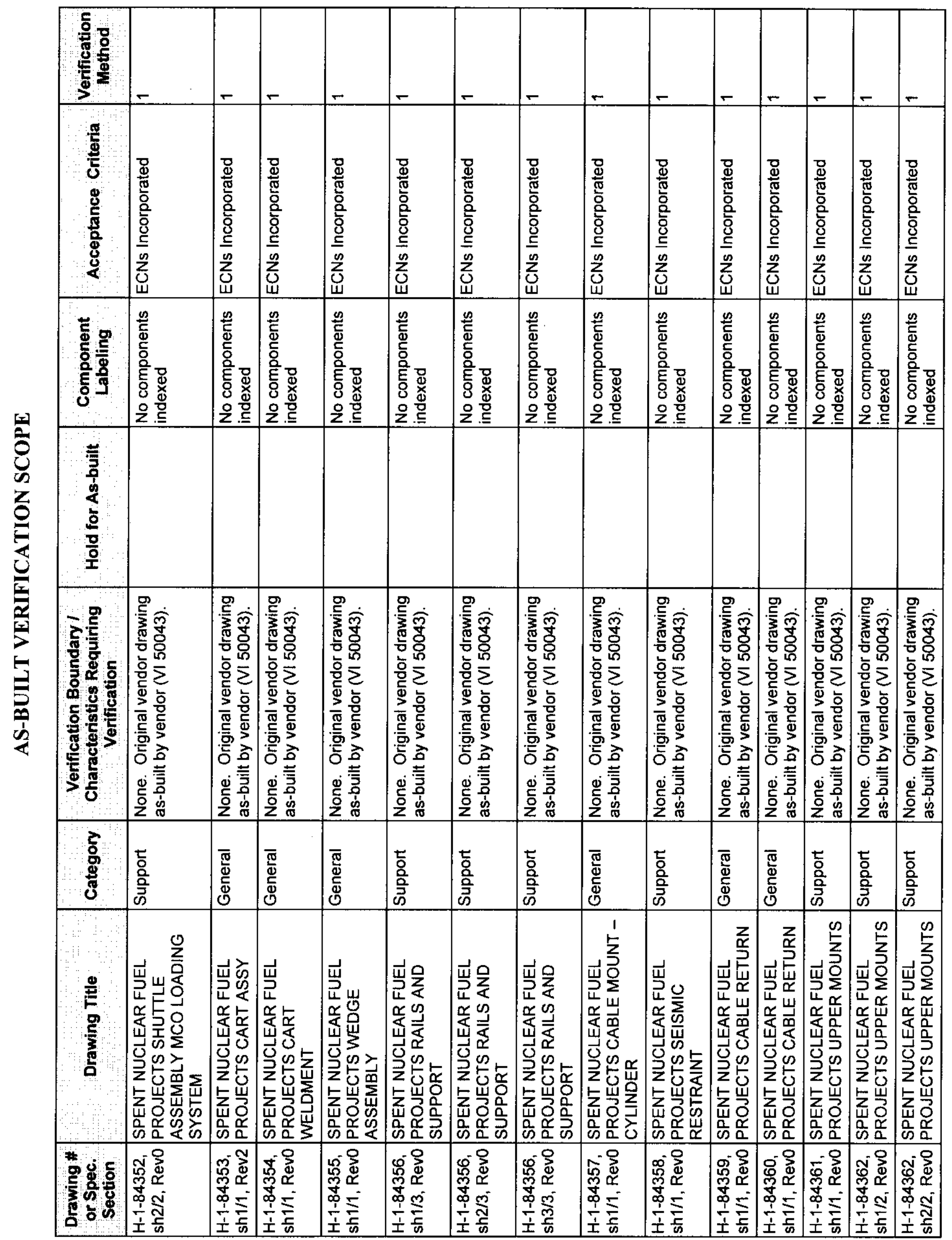


SNF-6103, Rev. 0

Project A.5/A.6

APPENDIX A

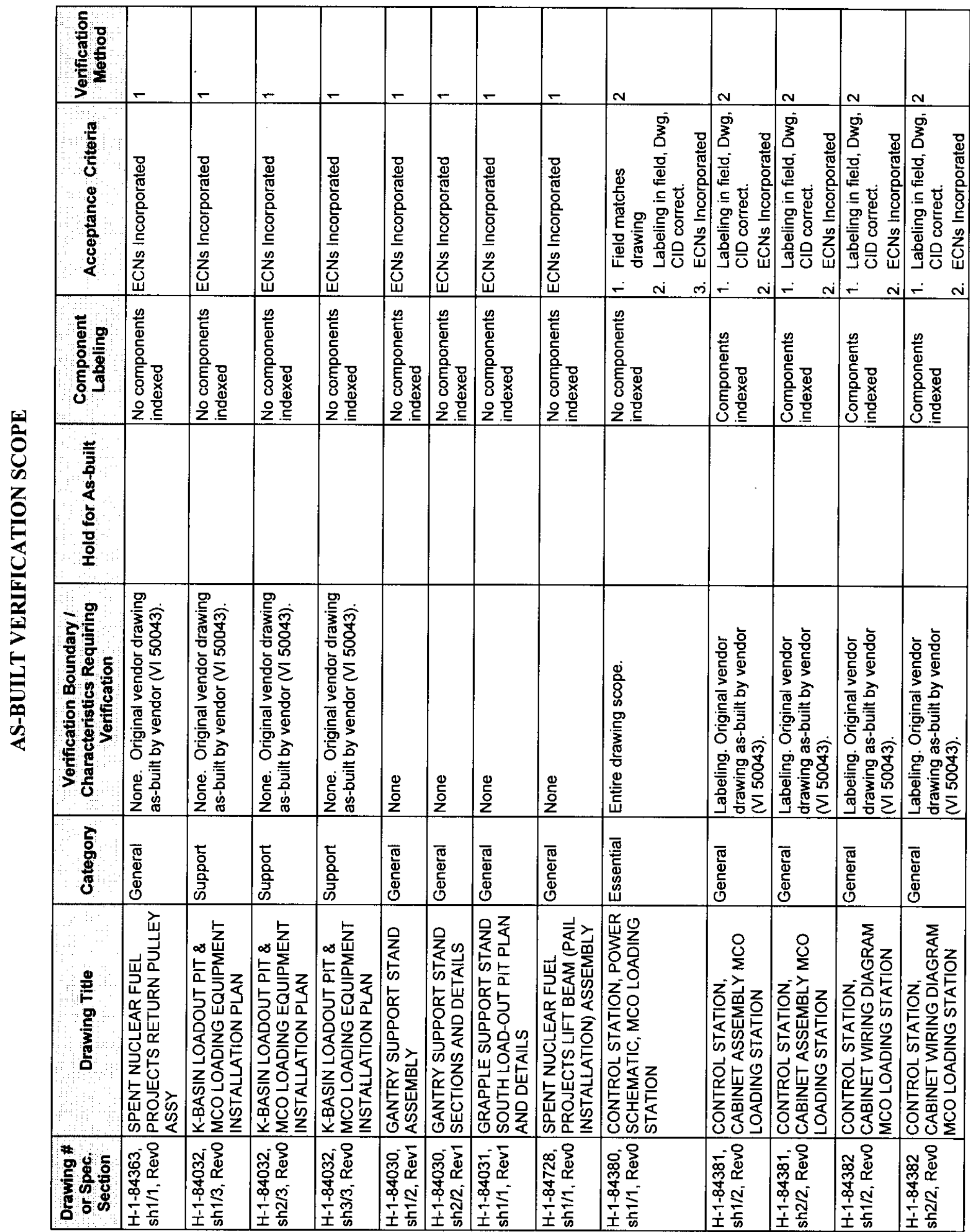


SNF-6103, Rev. 0

Project A.5/A.6

APPENDIX A

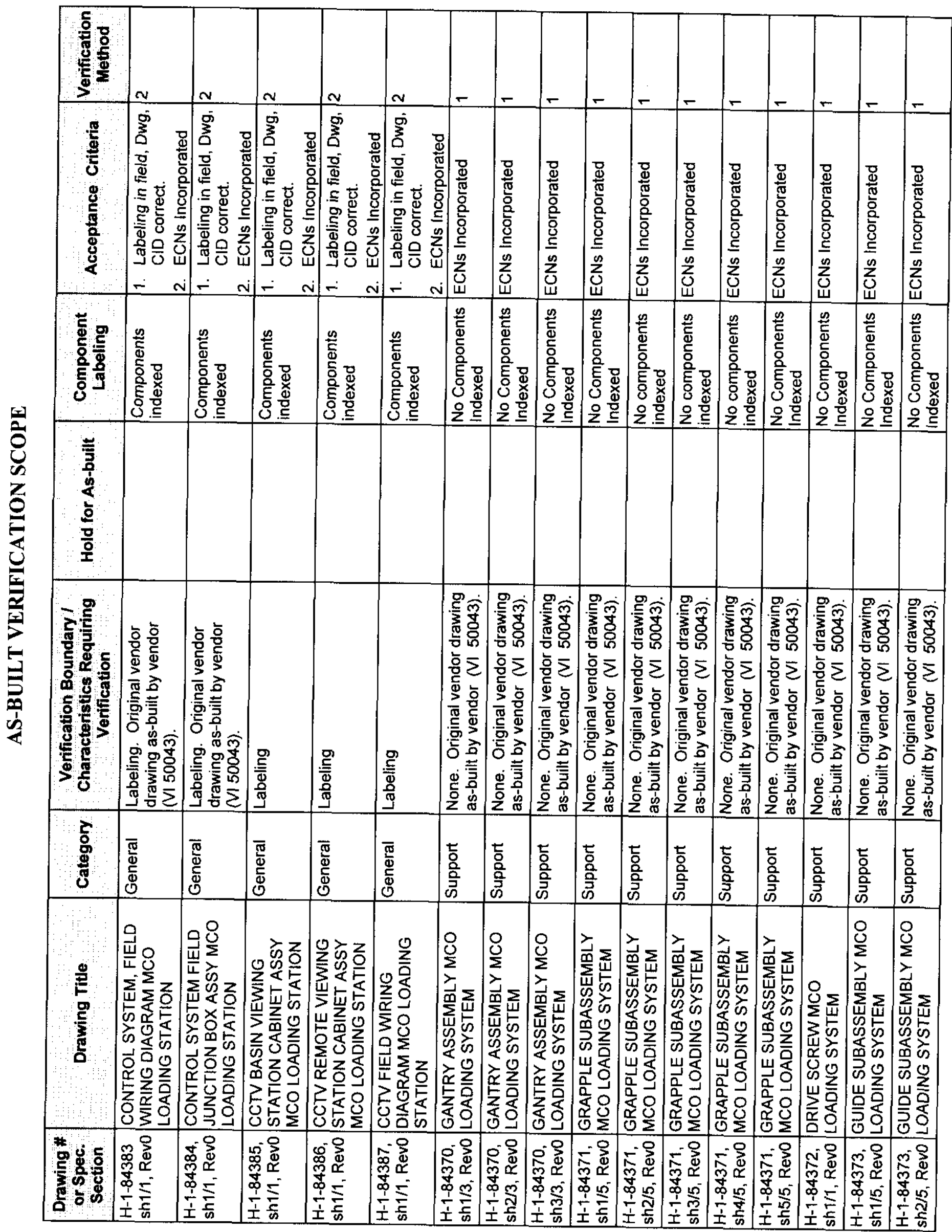

Page A-6 
SNF-6103, Rev. 0

Project A.5/A.6

APPENDIX A

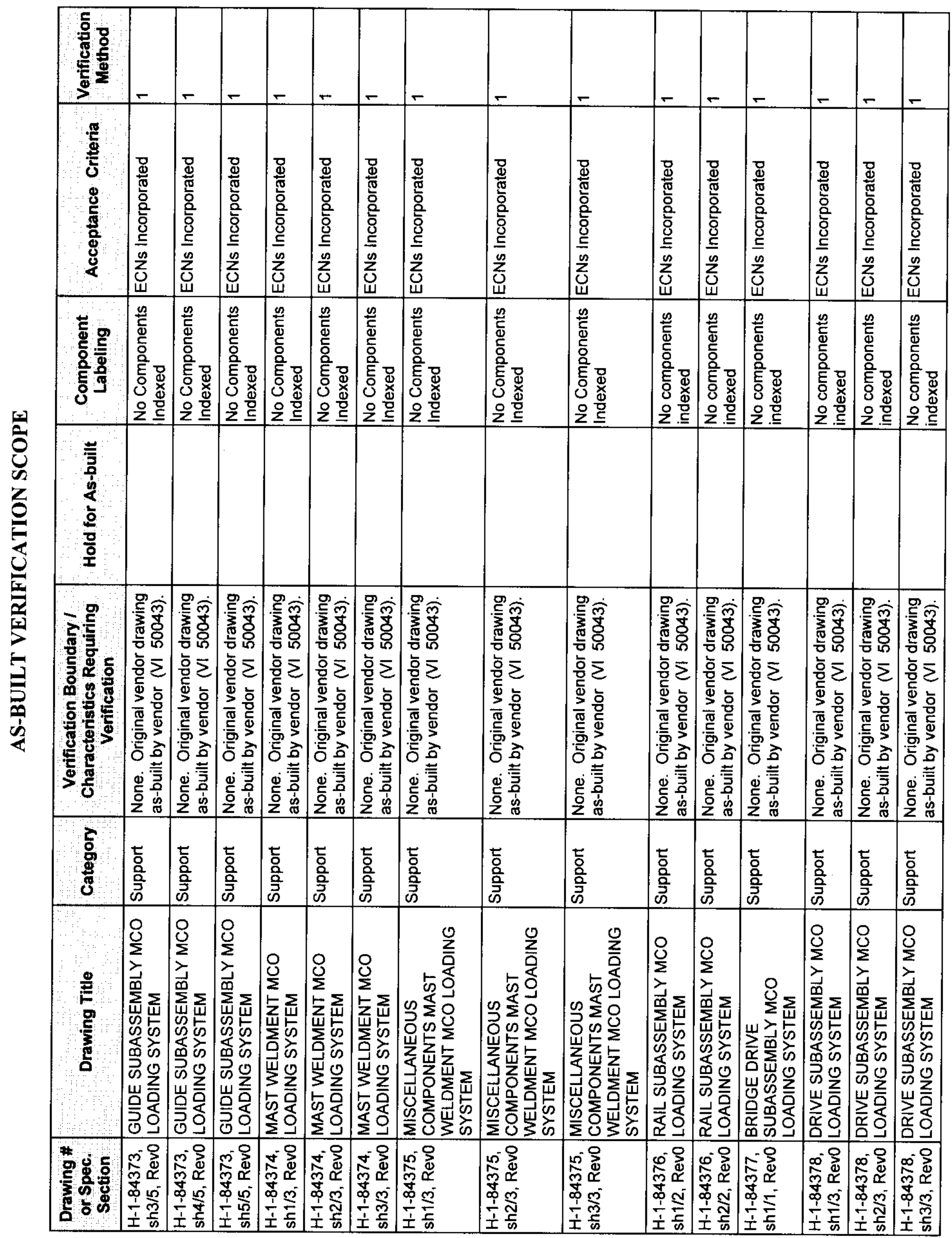


SNF-6103, Rev. 0

Project A.5/A.6

APPENDIX A

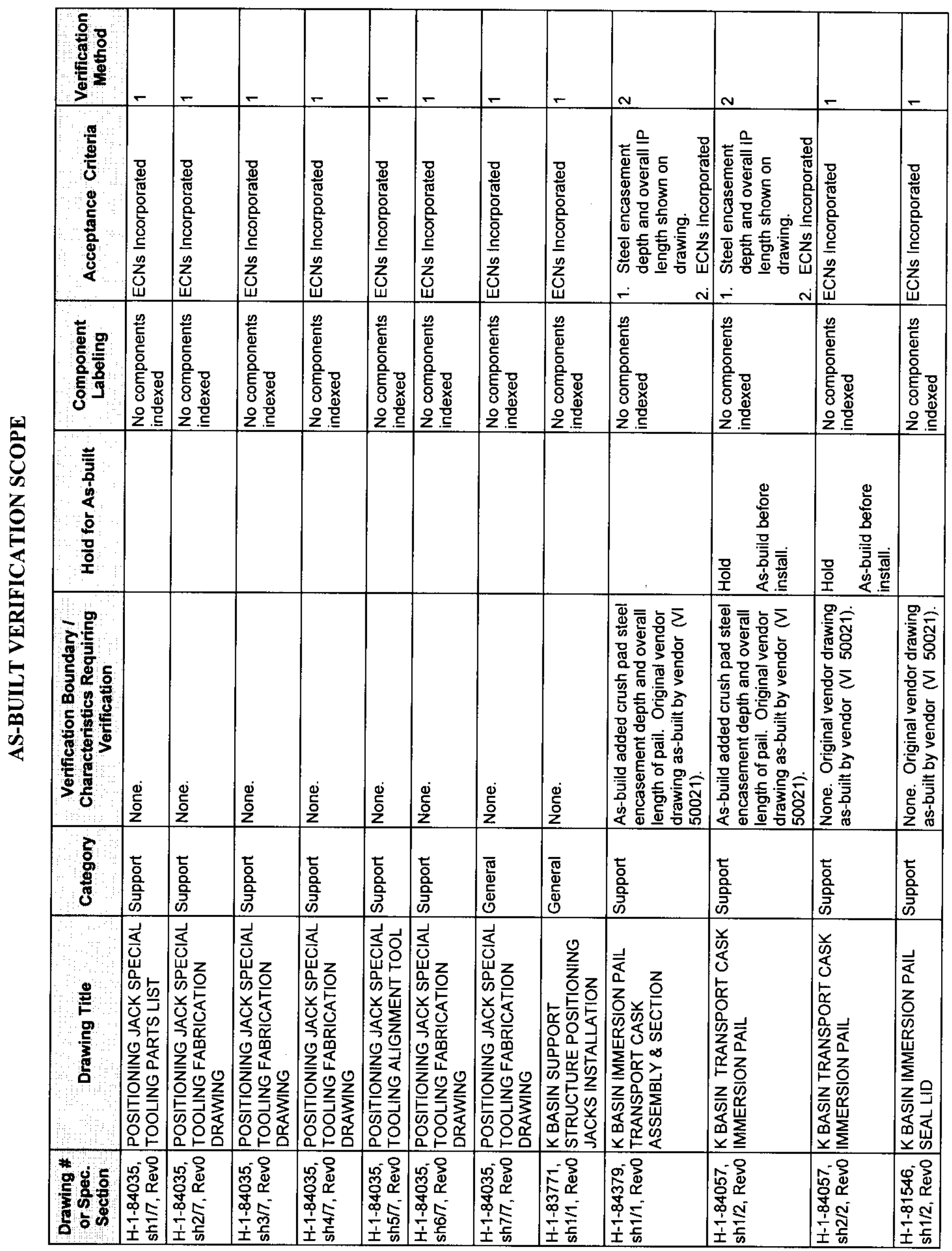

Page A-8 
SNF-6103, Rev. 0

Project A.5/A.6

APPENDIX A

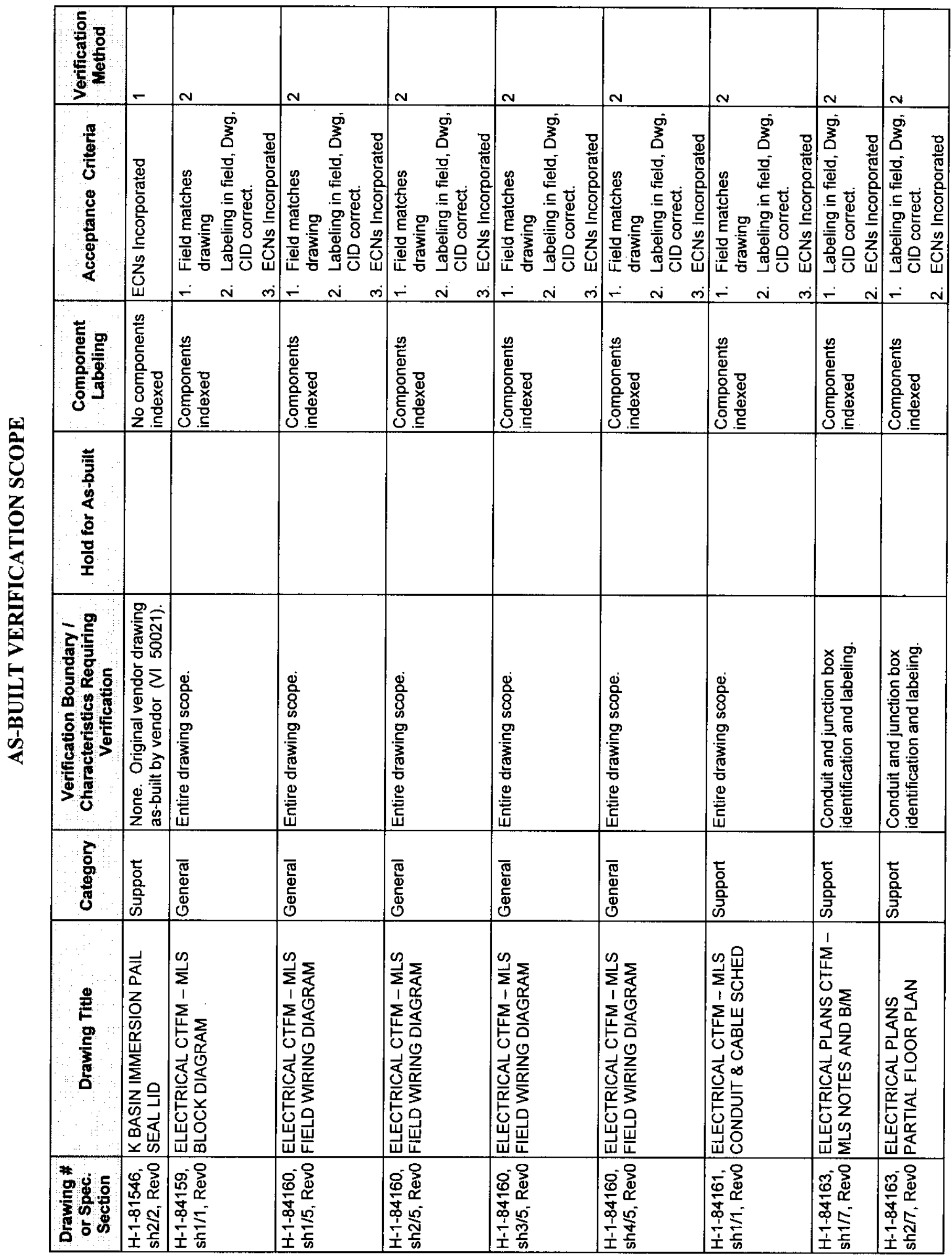

Page A-9 
SNF-6103, Rev. 0

Project A.5/A.6

APPENDIX A

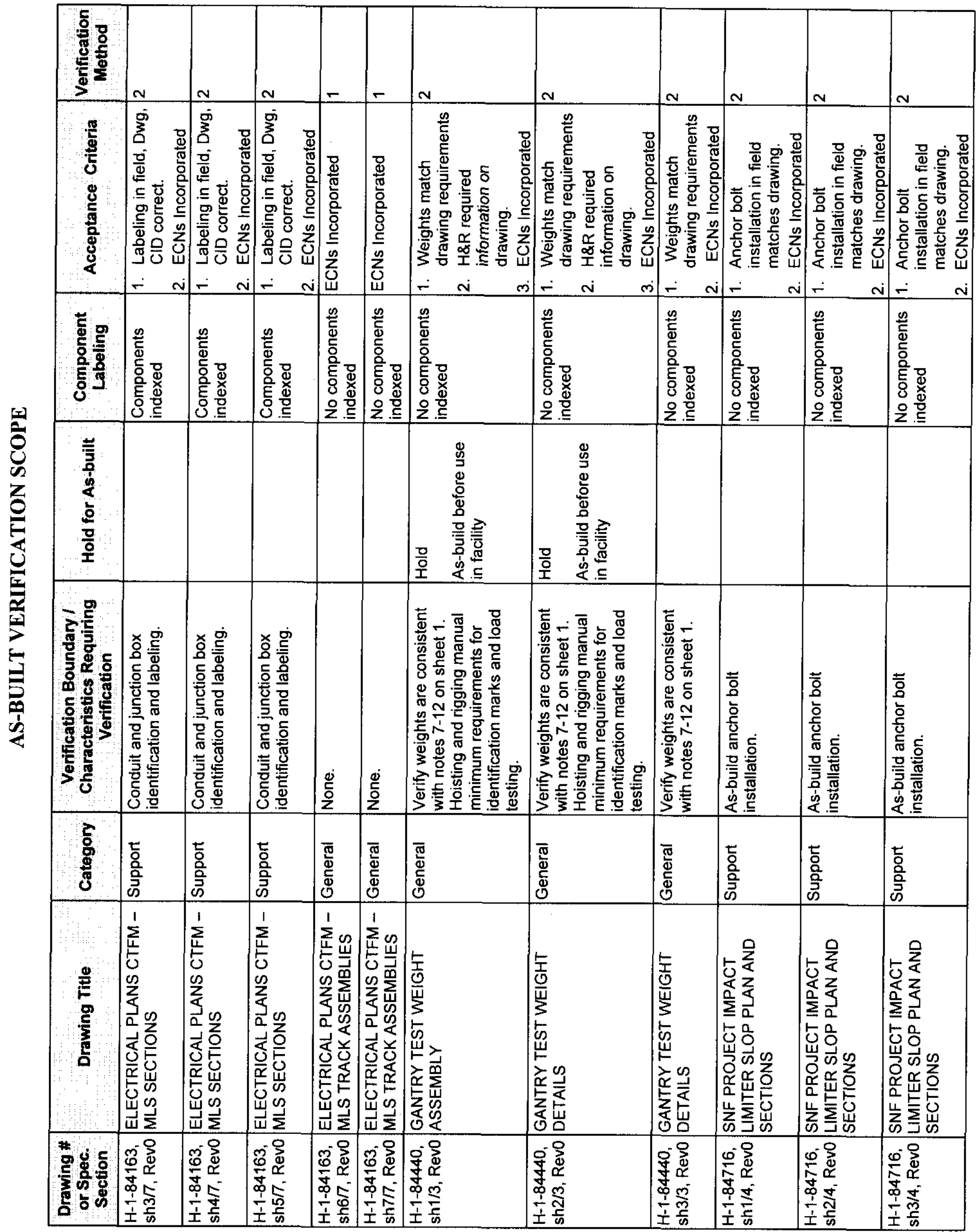

Page A-10 
SNF-6103, Rev. 0

Project A.5/A.6

APPENDIX A

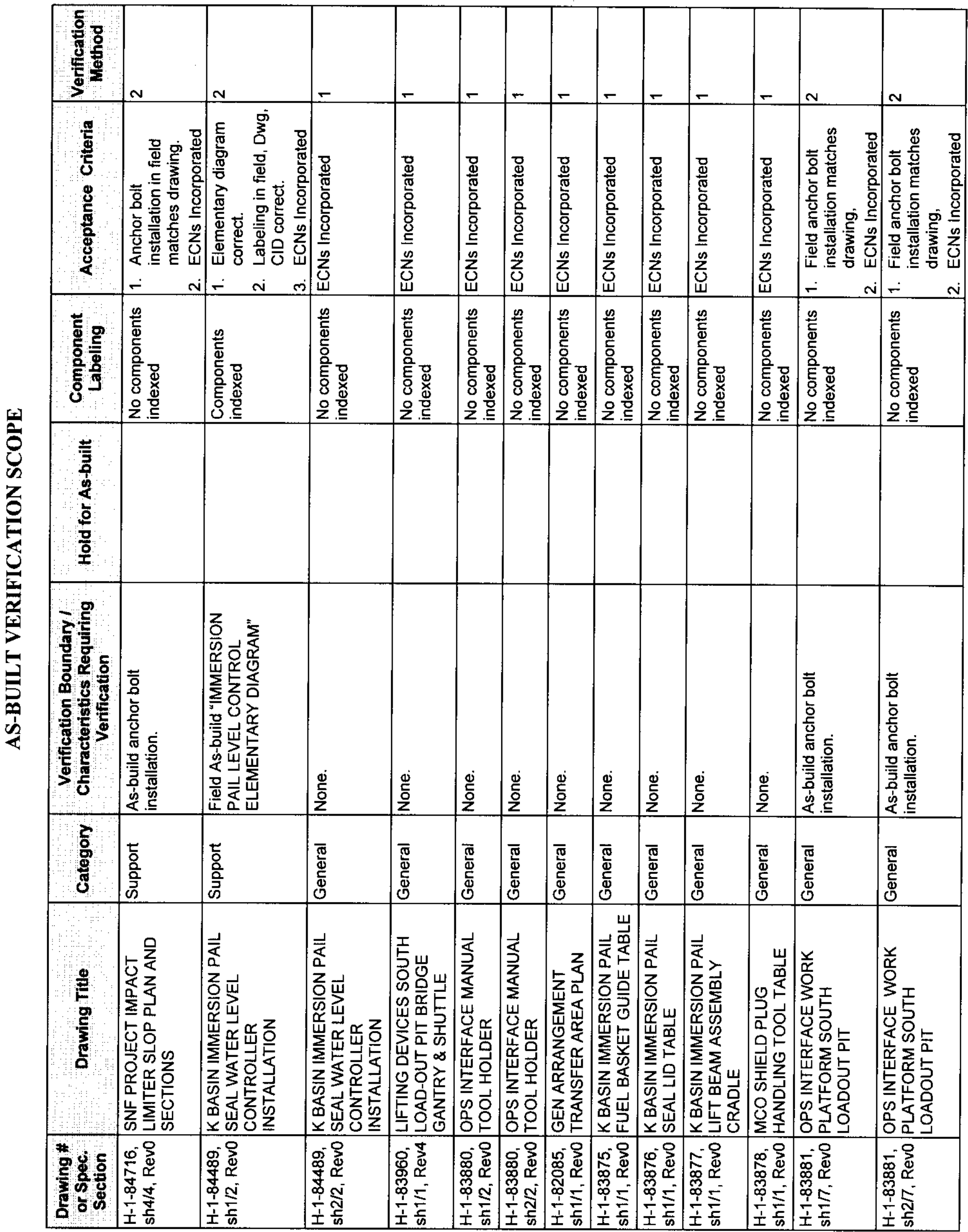


SNF-6103, Rev. 0

Project A.5/A.6

APPENDIX A

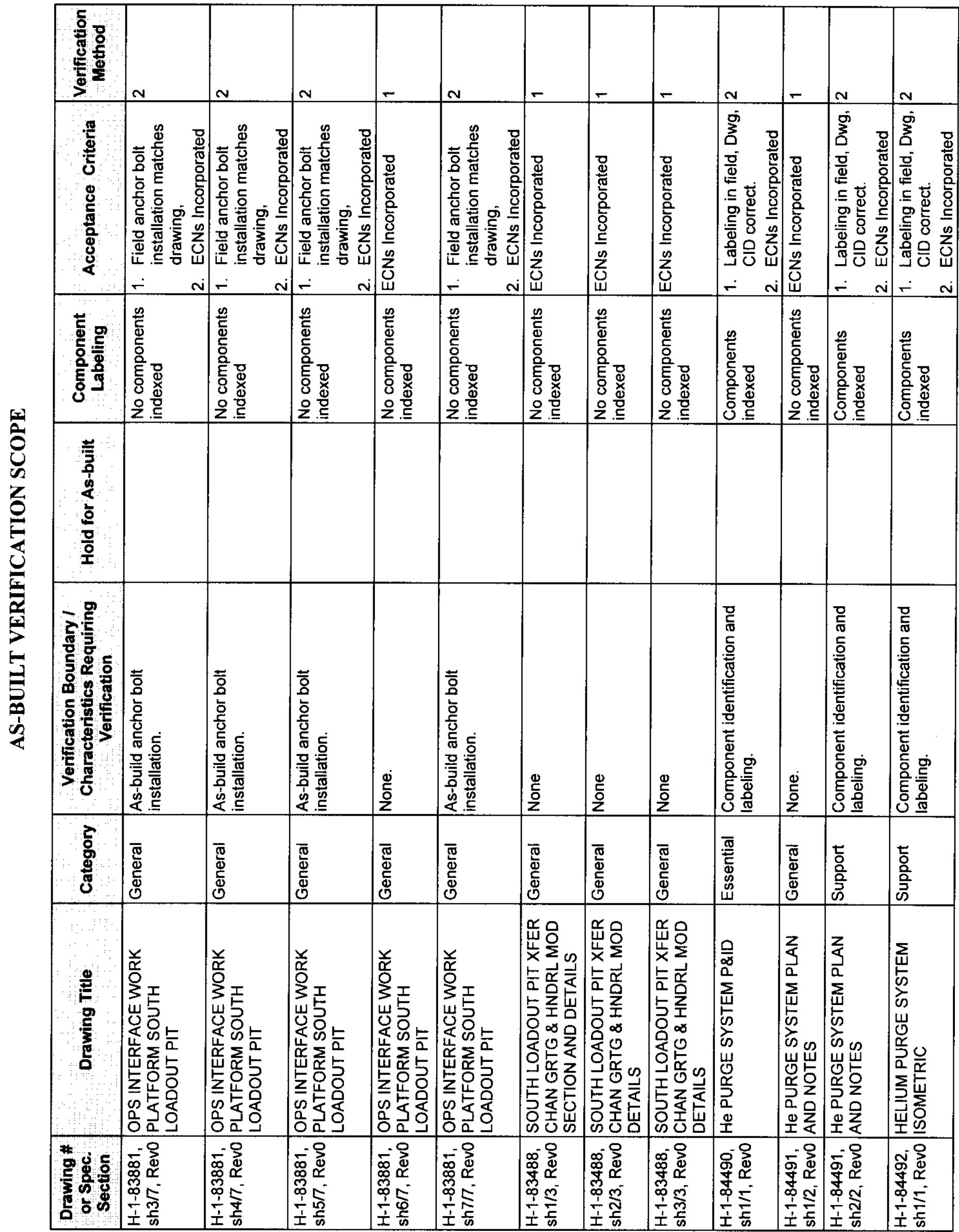

Page A-12 
SNF-6103, Rev. 0

Project A.5/A.6

APPENDIX A

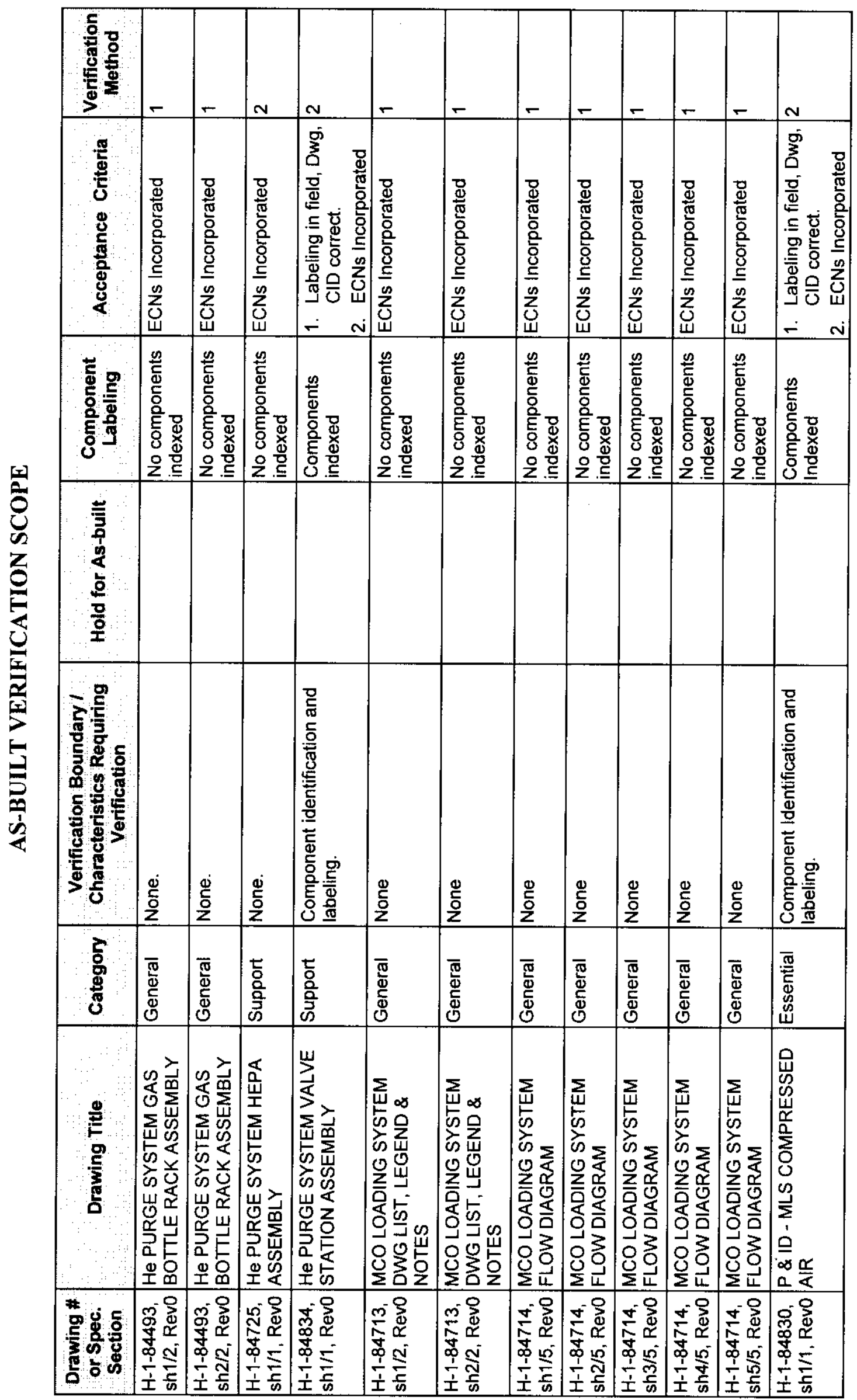

Page A-13 
SNF-6103, Rev. 0

Project A.5/A.6

\section{APPENDIX B}

\section{CTFM DEFICIENCY DATA SHEET}

\section{CONSISTING OF 2 PAGES}

INCLUDING COVERSHEET

Page B-1 
SNF-6103, Rev. 0

Project A.5/A.6

APPENDIX B

DISCREPANCY DATA SHEET

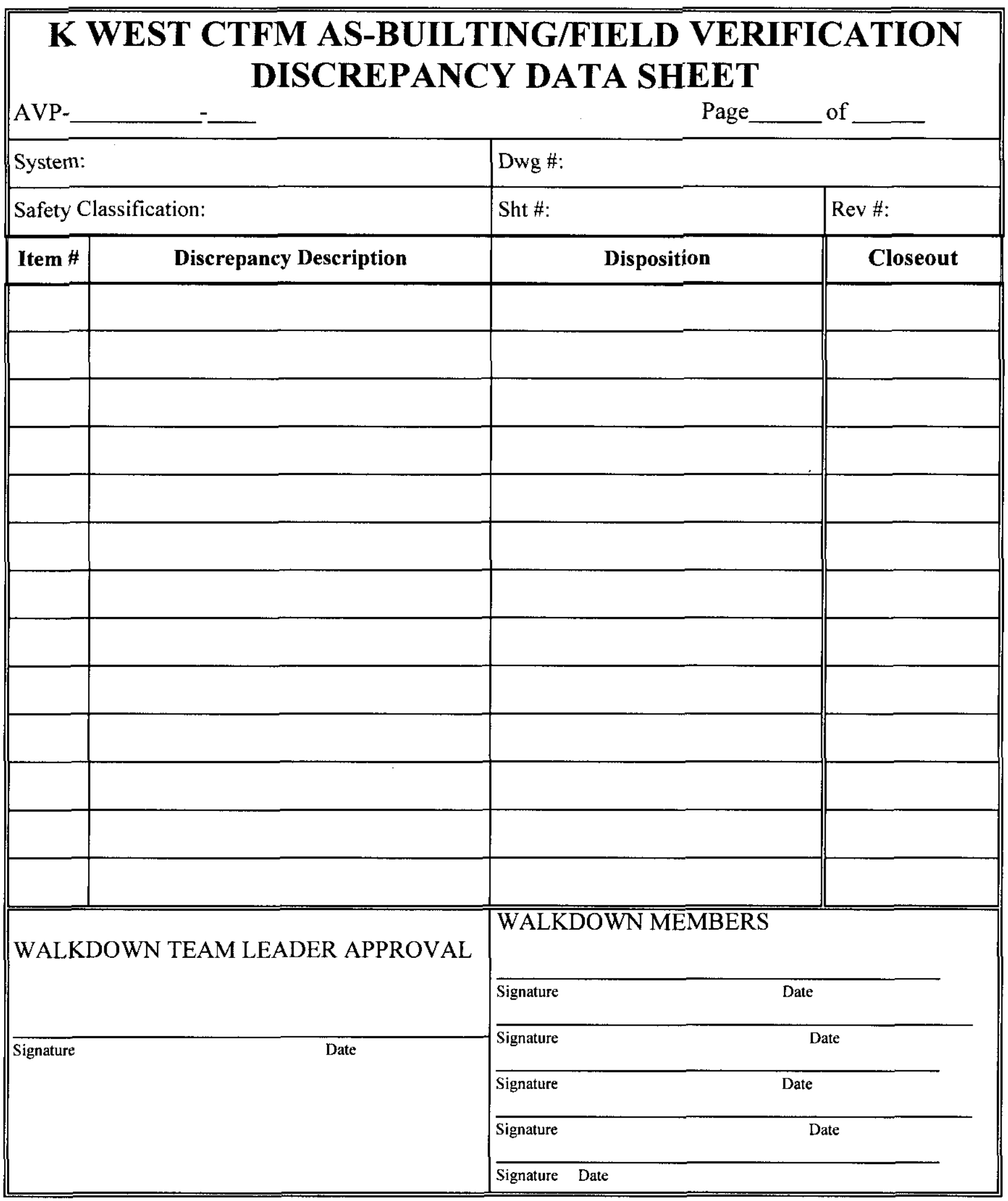




\section{DISTRIBUTION SHEET}

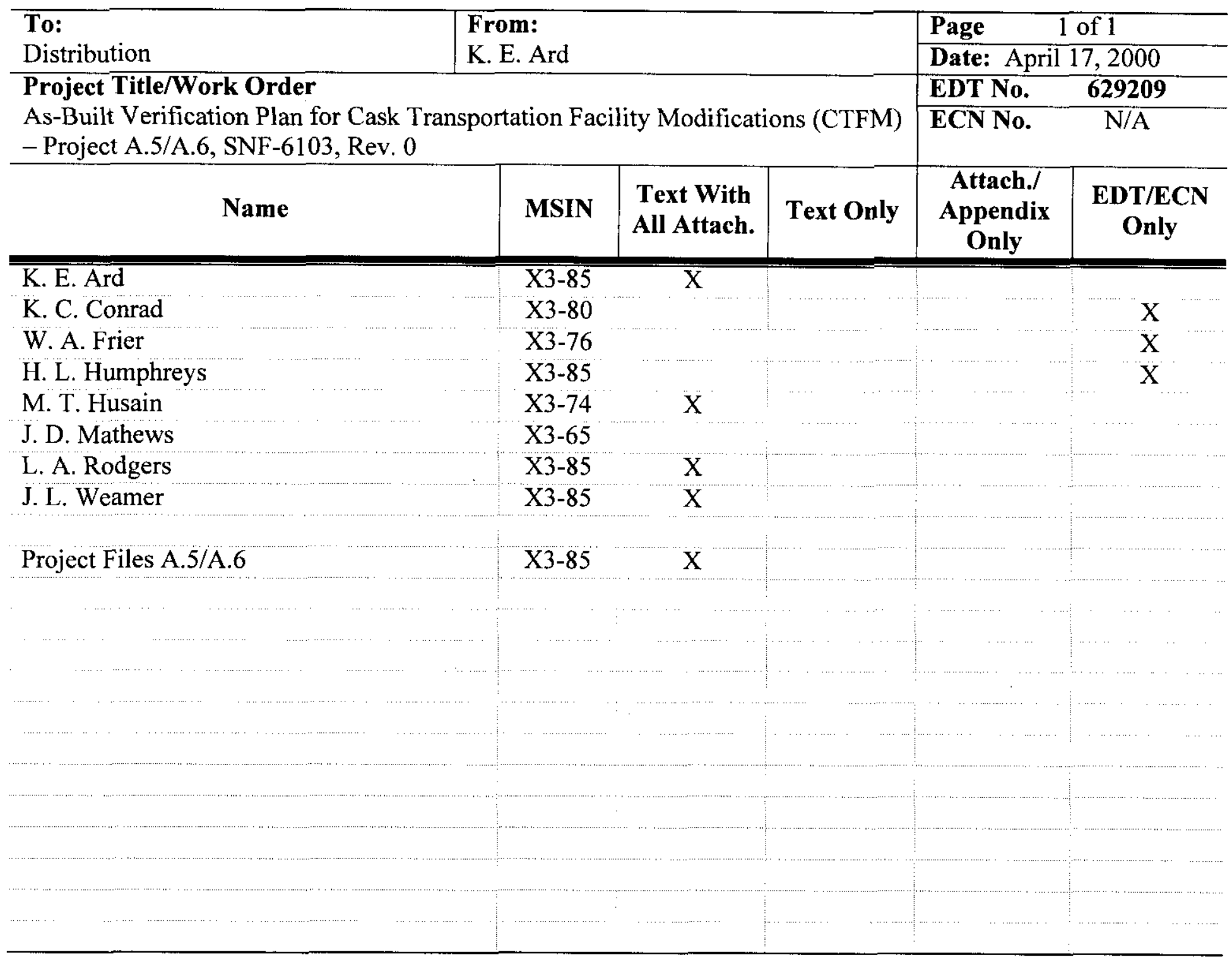

